\title{
Island Modeling Using Unstructured Grid during a Tropical Storm
}

\author{
Mourani Sinha, ${ }^{1}$ Ravi Kumar Yadav, ${ }^{2}$ and Paromita Chakraborty ${ }^{3}$ \\ ${ }^{1}$ Department of Mathematics, Techno India University, Saltlake, Kolkata 700091, India \\ ${ }^{2}$ Geological Survey of India, Hyderabad 500068, India \\ ${ }^{3}$ National Centre for Medium Range Weather Forecast, Noida, Uttar Pradesh 201309, India \\ Correspondence should be addressed to Mourani Sinha; mou510@gmail.com
}

Received 29 October 2015; Revised 6 January 2016; Accepted 17 January 2016

Academic Editor: Leonard J. Pietrafesa

Copyright (C) 2016 Mourani Sinha et al. This is an open access article distributed under the Creative Commons Attribution License, which permits unrestricted use, distribution, and reproduction in any medium, provided the original work is properly cited.

\begin{abstract}
The coastal wave dynamics of Agatti island situated on a coral atoll in Lakshadweep, India, having a notable topographic feature of steeper eastern shore over the western shore, is analysed in this study. A multinested model setup is generated using the global third-generation models WAM (Wave Modeling) and SWAN (Simulating Waves Nearshore). A high resolution unstructured grid is generated for the domain containing the island using SMS (Surface-Water Modeling System) interpolated with merged GEBCO (General Bathymetric Chart of the Oceans) and SRTM (Shuttle Radar Topography Mission) bathymetry. The SWAN model is integrated with a fine resolution of one minute by one minute during the tropical storm 01A (05-10 June 2004) which passed near the island. Model simulated significant wave height data when validated against satellite observations exhibited high accuracy. SWH (significant wave height) is observed to be greater for the west coast than that over the east coast of the island due to steeper eastern shore and there is widespread wave energy dissipation along the southwest direction of wave propagation during normal conditions. The one-dimensional energy density spectra generated during the storm period exhibit multimodality with structured and unstructured grids.
\end{abstract}

\section{Introduction}

Lakshadweep is an archipelago in the Arabian Sea $\left(8^{\circ}-\right.$ $12^{\circ} 3^{\prime} \mathrm{N}$ latitude and $71^{\circ} \mathrm{E}-74^{\circ} \mathrm{E}$ longitude) off the west coast of India and the region is well known for its coral diversity. Lakshadweep coral reefs are believed to play a significant role in the distribution and maintenance of coral reef biodiversity in India [1]. Various studies can be found conducted on the coral islands as they play crucial role in tourism, fishing, building materials, coastal protection, and providing new drugs and biochemicals [2]. Coral reefs protect the coastlines from storm damage, erosion, and flooding by reducing the wave action. Thus study of the coastal wave dynamics of the islands is of immense necessity.

Agatti island is the westernmost island of Lakshadweep, India. The latitude of the island is $10.8^{\circ} \mathrm{N}$ and longitude is $72.2^{\circ} \mathrm{E}$. The island is north-south elongated and is $7.5 \mathrm{~km}$ long. The width varies as we move north to south. It is $1000 \mathrm{~m}$ wide at its widest point in the northern part and tapers to almost as little as $100 \mathrm{~m}$ width in the south. The island is flat and rises around 2 to $3 \mathrm{~m}$ above the sea level. The southern part consists of a long narrow stretch of almost $2 \mathrm{~km}$ long and an average breadth of $100 \mathrm{~m}$. The area of human settlement of the island is mostly concentrated in the northern portion. Agatti is surrounded on all sides by a coral reef as an atoll like with prominence in the west side of the island. The western shore of the Agatti island is exposed to high waves during the southwest monsoon [3]. The coral growth on that part is strong so as to protect the island from the southwest monsoon. Reference [4] reports the widespread bleaching of the corals in 2010 at Agatti Island, Lakshadweep, India, and its ecological and socioeconomic impacts. Reference [5] shows human dependence on coral reefs in small islands based on socioeconomic assessments. Figure 1 gives the satellite imagery of the island.

The bathymetry of Agatti reveals an asymmetric cross section of the atoll. The western outer reef slope has a mild, gradual descent with relatively wide terraces at $4,7,13,25$, and 


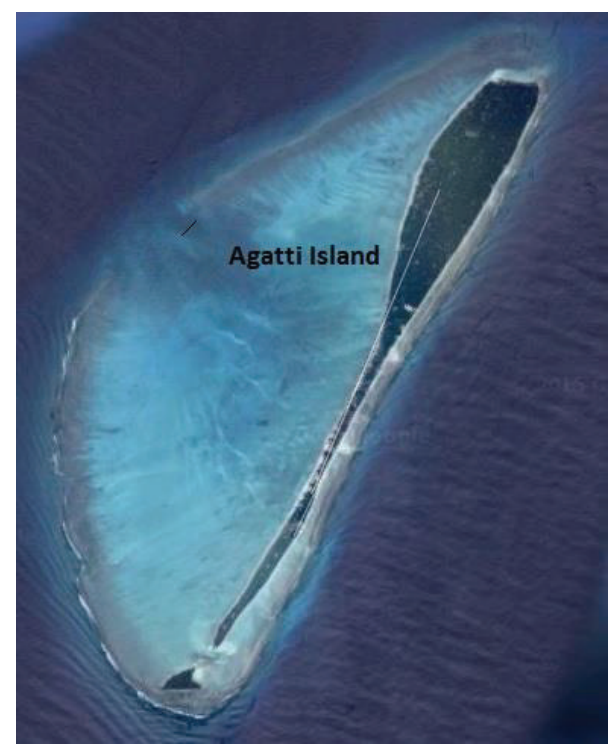

FIGURE 1: Satellite imagery of Agatti, Lakshadweep, India.

60 meters before it reaches 100-200-meter depths and then drops to 520-640 meters and eventually reaches the 1,300meter seabed. The eastern slope is steep, creates almost a wall with very narrow terraces, and reaches $200-300 \mathrm{~m}$ within 100 meters from the reef flat [1]. The general topography of Lakshadweep group of islands exhibits steeper shore on the east. As the slopes become steeper the effect of the gravity on the flow becomes greater and thus the beaches receive smaller wave heights.

Due to extensive reef on the western side, there is less possibility of the islands being eroded along this coast, whereas the eastern sector of the island is subjected to the direct furry of the wave action causing the erosion [6]. Studies indicate that the island is quite stable for a considerable time and it will continue to remain stable provided that proper steps are taken to prevent the erosion. There have been several studies on the geomorphic features of the island; however, the study of the island topography from the dynamical view point is being done for the first time. Hence such analyses are prerequisite to understand the topography and coastline features, on the basis of the effects of wind generated waves, energy densities, and conservation of mass or mass transport.

Numerical models can be used most effectively to compute wind generated surface waves. Fine grid models are required for coastal regions which have varying bathymetry, while for deep waters coarser grids can generate accurate wave parameters with less computational time. The advantages of unstructured grids used to represent regions of strong bathymetry variations have been mentioned in many contexts. They not only reduce the number of computational grid points but also conserve spatial resolution in the shallow water region. In this paper we have generated a multinested model setup for the domain containing the island using the models WAM 4.5.3 and SWAN 40.91. The purpose of the study is to compute and validate significant wave height along the coast of the island and analyse energy density spectra for certain locations, so as to understand the coastal dynamical features of the island.

\section{Materials and Methods}

2.1. Models. WAM is one of the most extensively tested wave models in the world and is well documented. A detailed description of the WAM code is given by $[7,8]$. SWAN is a third-generation wave model, developed at Delft University of Technology, which computes wind generated surface gravity waves in coastal regions and inland waters. The model is based on the wave action balance equation with sources and sinks. Although WAM and SWAN are both third-generation wave models which compute random short-crested wind generated waves, WAM is primarily developed for deep water ocean waves, whereas SWAN has been developed specifically for coastal and inland waters. In spite of the fact that both codes can be used for shallow and deep water calculations it must be noted that the application of SWAN on ocean scales is not recommended from an efficiency point of view. The numerical model SWAN is able to characterize sea waves in nearshore regions taking into account the presence of currents and wind generated waves. This model was developed at the Technical University of Delft [9] and it can be considered the nearshore version of the WAM model [10]. An unstructured grid algorithm for SWAN presented by [11] is reported to be numerically accurate and robust in its ability to simulate wave fields over shelf seas, in coastal areas and shallow lakes, while being sufficiently flexible to permit desired local mesh refinements in such areas. SWAN considers two types of grids, namely, structured and unstructured. Structured grids may be rectilinear and uniform or curvilinear whereas unstructured grids may contain triangles or a combination of triangles and quadrilaterals. In the current version of SWAN, however, only triangular meshes can be employed.

The spatial scales of the wind waves propagating from deep to shallow waters are very different. Thus mesh refinement near the coast is required to be implemented without operating costs associated with grid adaptation at some distance offshore. Generally this is done with the help of nested models in which first waves are generated on a coarse grid for a larger region and then on a finer grid for a smaller region using the coarse grid generated boundary conditions. As stated in the SWAN manual, the use of unstructured grids offers a good alternative to nested models not only because of the ease of optimal adaption of mesh resolution but also because of the modest effort needed to generate grids about complicated geometries, for example, islands and irregular shorelines.

This type of flexible meshes is particularly useful in coastal regions where the water depth varies greatly. As a result, this variable spatial meshing gives the highest resolution where it is most needed. The use of unstructured grids facilitates resolving the model area with a relative high accuracy but with a much fewer grid points than with regular grids.

In our study to simulate the waves in the domain containing the island we have used the deep water model 
WAM for the coarse run to include the impact of the southern ocean swells and then using the boundary conditions the structured grid run and finally the unstructured grid run for the complex geometry.

2.2. SMS. SMS (Surface-Water Modeling System) is developed by the Environmental Modeling Research Laboratory. SMS can be used to construct 2D and 3D finite element meshes and finite difference grids of rivers, estuaries, bays, or wetland areas. The tools include a sophisticated set of creation and editing tools to handle complex modeling situations with relative ease. Several methods of finite element mesh creation are available, allowing you to create any combination of rectangular and triangular elements needed to represent your model domain. Both cartesian and boundary-fitted grid creation tools are available to allow representation of a model domain for finite difference models. The powerful mesh or grid creation tools, coupled with GIS objects, are what makes SMS such an easy-to-use and accurate modeling system.

2.3. Data. For this study, we have used six hourly and $0.5-$ degree QSCAT/NCEP blended ocean winds as forcing to the wave models. The ocean surface wind data is derived from spatial blending of high resolution satellite data (SeaWinds instrument on the QuickSCAT satellite (QSCAT)) and global weather center reanalyses (NCEP). Bathymetry derived from ETOPO5 is given as input to the coarse model runs and those derived from ETOPO1 are given as input to the fine model runs. GEBCO (http://www.gebco.net) data and SRTM (http://srtm.csi.cgiar.org/) topography data are used to generate the unstructured grid. Model simulations are compared with Envisat track altimeter data to check accuracy.

2.4. Model Experiments. A multinested model setup is generated consisting of (i) coarse run followed by (ii) regional run and finally (iii) location specific model run using unstructured grid. For the coarse run the WAM model is integrated for the whole Indian Ocean $\left(30^{\circ} \mathrm{E}\right.$ to $120^{\circ} \mathrm{E}$ in longitude and from $70^{\circ} \mathrm{S}$ to $30^{\circ} \mathrm{N}$ in latitude) with NCEP blended wind and ETOPO5 bathymetry of resolution $0.5 \times 0.5$ degrees to generate the boundary condition for the regional model run. Then for the regional domain the nested structured SWAN model is compiled for $71^{\circ} \mathrm{E}-73^{\circ} \mathrm{E}$ and $10^{\circ} \mathrm{N}-12^{\circ} \mathrm{N}$ in the Arabian Sea with $1^{\prime} \times 1^{\prime}$ resolution to generate the boundary condition for nested unstructured SWAN run. Finally the location specific model is used with unstructured grid for the region $71.7^{\circ} \mathrm{E}-72.7^{\circ} \mathrm{E}$ and $10.5^{\circ} \mathrm{N}-11.5^{\circ} \mathrm{N}$ to compute the wave parameters. Figure 2 depicts the regions of multinested model run.

For generating the unstructured grid, first we merged the GEBCO (http://www.gebco.net) data of 1 arc-minute $(1.8 \mathrm{~km})$ resolution and SRTM (http://srtm.csi.cgiar.org/) topography data (3 arc-seconds or $90 \mathrm{~m}$ ) extracted for the domain of study. The merged data is then interpolated to the mesh with clear coast line using SMS. Hence the grid generated given by Figure 3 has minimum grid size of 30 meters and maximum grid size of 550 meters. Thus a multinested model setup is developed and taking into account the tropical storm 01A (05-10 June 2004) (http://weather.unisys.com/hurricane/), shown in Figure 4 which passed near the Agatti island, the model is run during the storm period.

\section{Results and Discussion}

In this experiment, the multinested models are run for the months of May, June, and July 2004. For a particular grid point $\left(72.208^{\circ} \mathrm{E}, 10.879^{\circ} \mathrm{N}\right)$, computed $\mathrm{SWH}$ are compared for structured and unstructured SWAN model simulations (Figure 5(a)). The trend observed from the figure depicts reasonable accuracy of the magnitude of the significant wave heights. The correlation coefficient calculated is 0.5 and this may be due to high resolution and complex grid generation method used for the unstructured case. When normal conditions prevail, SWH ranges from 2 to $2.5 \mathrm{~m}$ for both structured and unstructured cases. During the storm period SWH increases up to $2.5 \mathrm{~m}$ for the unstructured and $3.5 \mathrm{~m}$ for the structured model. There is an underprediction of the SWH values for the unstructured SWAN run compared to structured run which may be attributed to the different boundary conditions given to both runs. The boundary conditions given to the structured SWAN run includes the impacts of the southern ocean swells generated by the coarse WAM run. The unstructured SWAN run uses the boundary conditions from the structured run and thus may not include the swell impacts efficiently.

Figure 5(b) shows the spatial plots for the structured and unstructured SWAN runs during normal conditions. In this case the time chosen is 31 May 2004, 00 hours. For both plots the wave heights are between 1 and 4 meters. The unstructured plot shows strong wave dissipation, after the waves travel across the reef, along the southwest direction in which the waves also propagate in May. The wave heights become smaller because of breaking and frictional resistance. Figure 5(c) represents similar plots during storm period. Here the time chosen is 08 June 2004, 00 hours. Higher wave conditions prevail for the entire region with wave dissipation less widespread. There is under prediction for the unstructured runs for both the normal and storm conditions.

Figures 6(a) and 6(b) give the SWH plots for the unstructured SWAN run at the initial stage (5 June, $18 \mathrm{hrs}$ ) of the storm and at the matured stage (10 June, 00 hrs) of the storm. For the entire domain SWH ranges between 1 and $3.5 \mathrm{~m}$ at the initial stage and it increases to $4.5 \mathrm{~m}$ as the storm matures. To understand the dynamics of the wave parameters along the Agatti coast we have selected a box containing the island which is magnified and shown in the figure. Initially the SWH is approximately 1 meter on the east coast of the island and approximately 2 meters on the west coast. There are several studies which report the higher wave height on the western shore of the island during the southwest monsoon. As mentioned earlier the western outer reef slope of Agatti has a mild, gradual descent while the eastern slope is steep.

As the storm intensifies, the SWH increases to about 2 meters in the east coast and about 3 meters in the west coast. The higher SWH at the west coast over the east coast can be attributed to steeper shore on the eastern side. As the waves reach the steeper bottom there is reduction in the heights faster. 

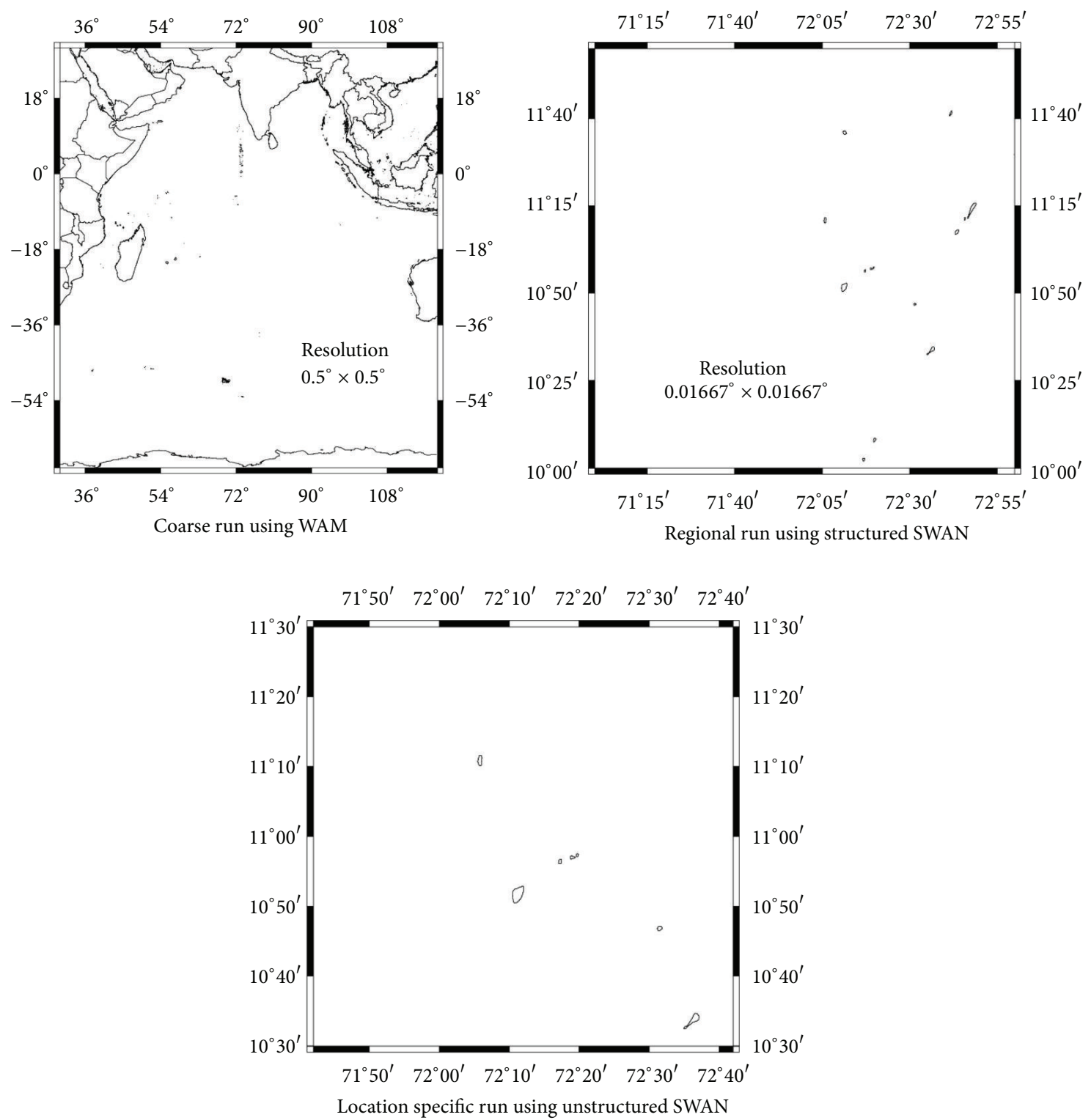

FIGURE 2: Regions of multinested model setup.

The accuracy of the simulations is checked by comparing the model computed SWH with Envisat track altimeter data. Figure 7 shows that the track generated for 08 June 2004, 18 hours, matches reasonably the spatial plot generated by SWAN. At the grid point $\left(71.06^{\circ} \mathrm{E}, 10.63^{\circ} \mathrm{N}\right)$, model computed $\mathrm{SWH}$ is 4.2 meters, whereas satellite observed $\mathrm{SWH}$ is 4.1 meters. The comparison is satisfactory as per the availability of the satellite data.

Next the one-dimensional energy density spectra are generated at the grid point $\left(72.208^{\circ} \mathrm{E}, 10.879^{\circ} \mathrm{N}\right)$ during the storm period and normal period for the structured and unstructured SWAN run. Figure 8(a) generated by the structured SWAN run for 5 June when the storm began gives a single peak of the spectrum as compared to the double peak in Figure 8(b) for the unstructured run. During normal conditions (25 June) Figure 8(c) gives a double peak for the structured run, whereas Figure 8(d) gives a single peak for the unstructured run. The figure shows that the magnitudes of the wave energies match for structured and unstructured runs although the shape of the spectra varies.

\section{Conclusions}

A multinested model setup for Agatti island is successfully generated with unstructured grid and high resolution of one minute by one minute. The grid generated has minimum grid size $30 \mathrm{~m}$ and maximum grid size $550 \mathrm{~m}$. There is reasonable accuracy in the trends of the computed SWH for structured and unstructured runs during the normal and storm periods. The maximum wave height during the storm reaches $4.5 \mathrm{~m}$. The SWH is higher on the west coast of the island compared to the east coast due to steep eastern 


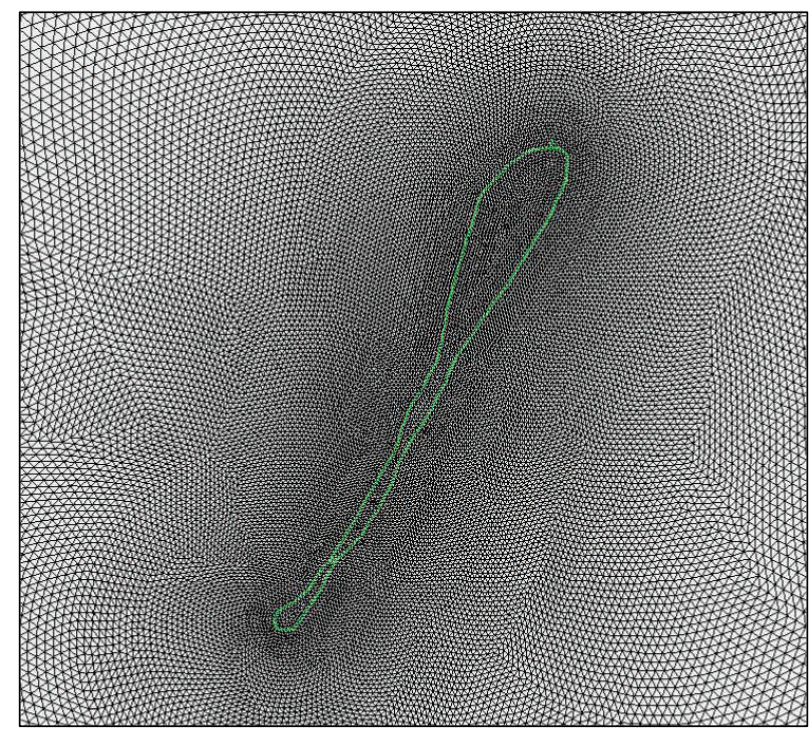

Grid area: $1^{\circ} \times 1^{\circ}$

Latitude: $10.5^{\circ} \mathrm{N}$ to $11.5^{\circ} \mathrm{N}$

Longitude: $71.7^{\circ} \mathrm{E}$ to $72.7^{\circ} \mathrm{E}$

Minimum grid size: 30 meters

Maximum grid size: 550 meters

FIGURE 3: Unstructured grid for Agatti island generated by SMS.

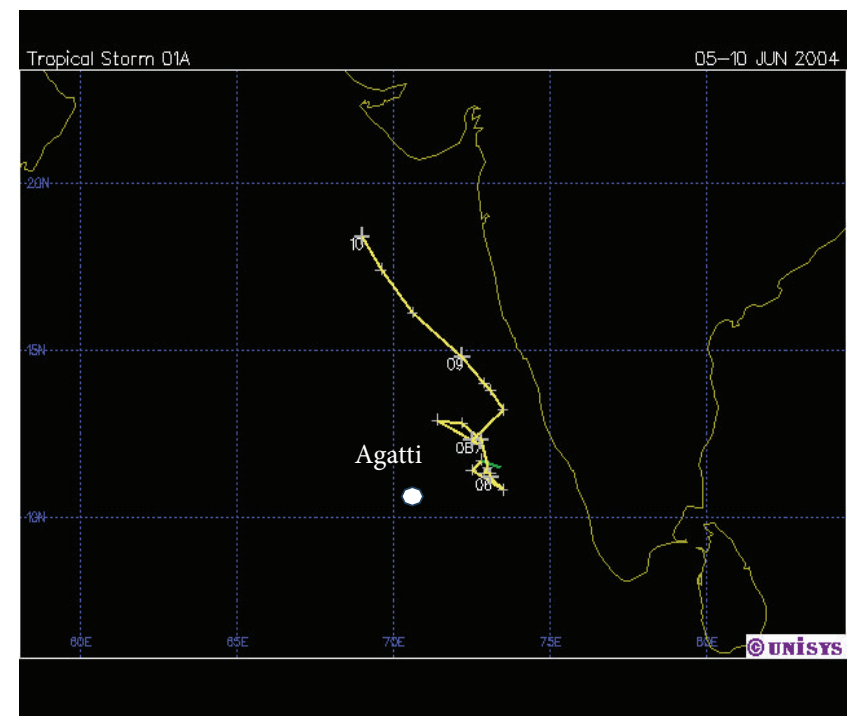

FIGURE 4: Track of tropical storm 01A (05-10 June 2004).

slope of the island. There is widespread dissipation of wave energy during normal conditions after the waves cross the reef. For the SWAN computations satellite validation of the SWH data is satisfactory. Energy density spectrums are compared during normal and storm conditions for structured and unstructured runs and it is concluded that although the magnitudes match the shape of the spectrum varies. The coral reef islands play an important role in shaping the ecosystems that have inhabited our tropical oceans for many million years. The inhabitants are vulnerable to extreme wave conditions and hazards and thus long term study of wave climate of such regions is a necessity.

\section{Conflict of Interests}

The authors declare that there is no conflict of interests regarding the publication of this paper. 


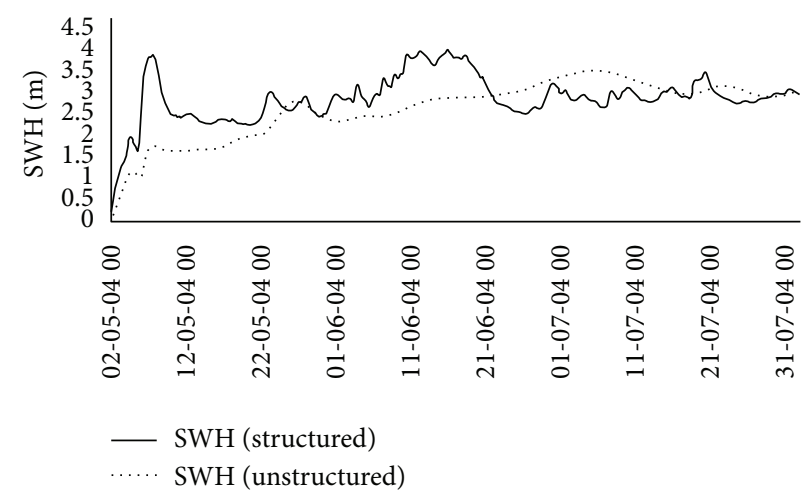

(a)
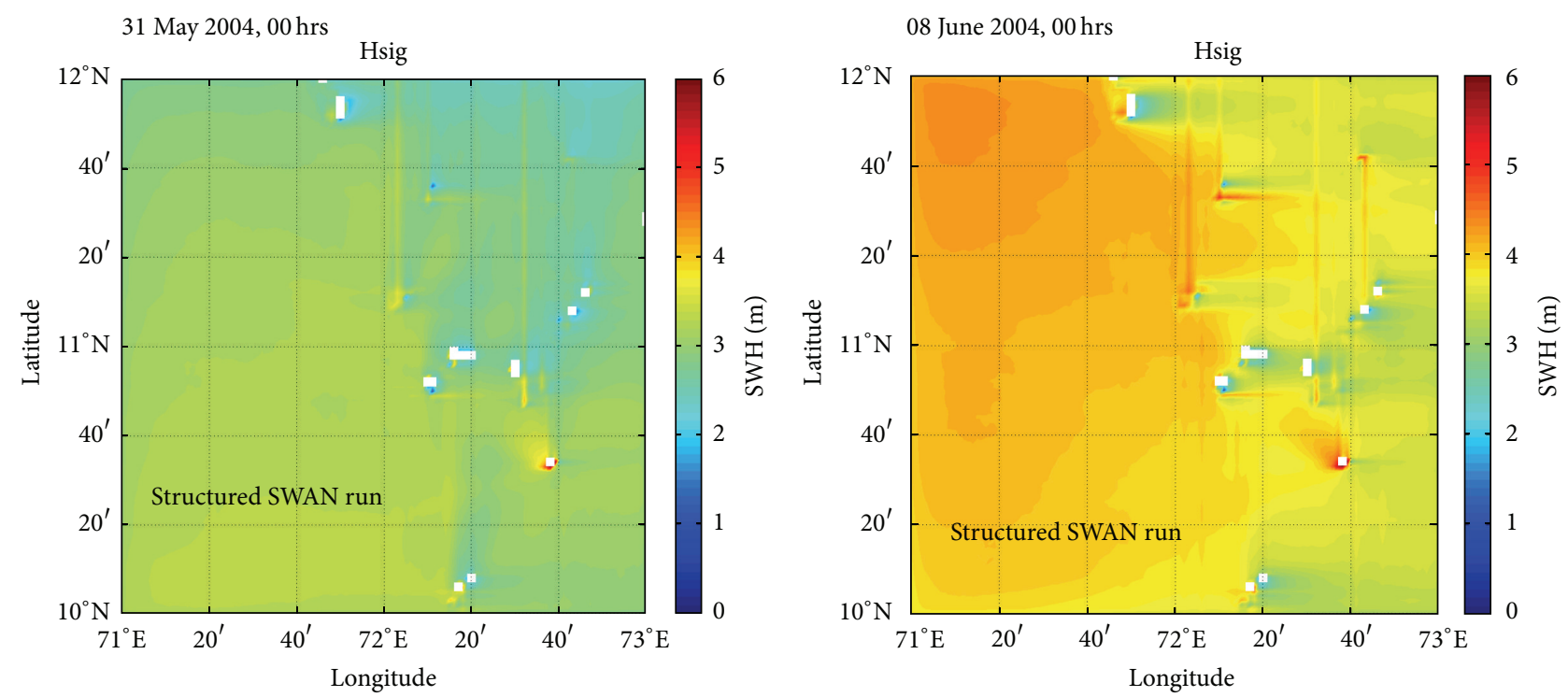

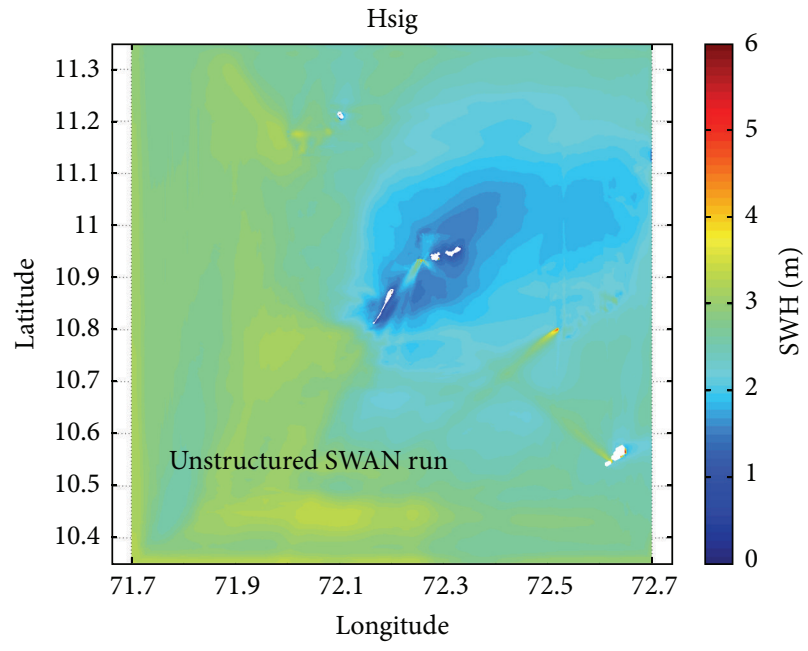

(b)

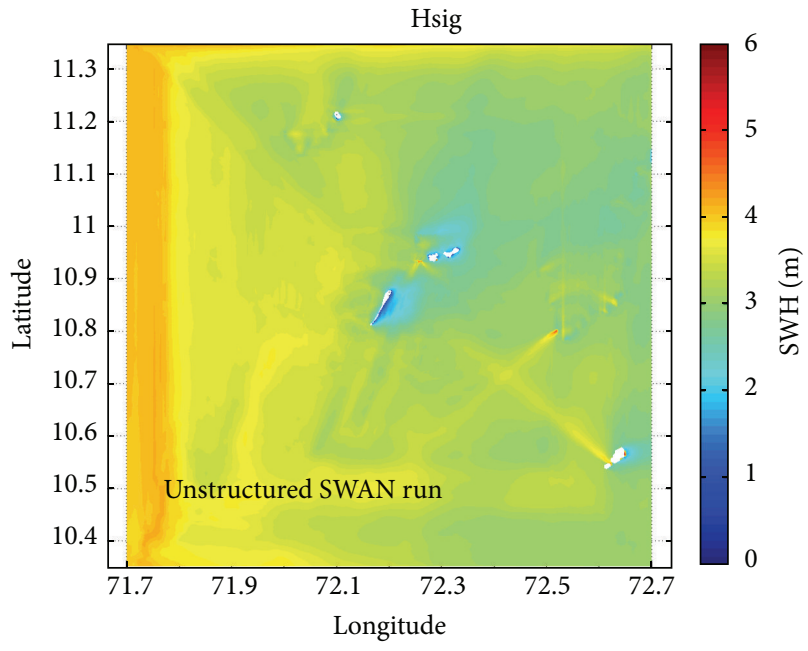

(c)

FIGURE 5: (a) SWH for structured and unstructured SWAN at $72.208^{\circ} \mathrm{E}, 10.879^{\circ} \mathrm{N}$. (b) SWH plots for structured and unstructured SWAN runs during normal conditions. (c) SWH plots for structured and unstructured SWAN runs during storm conditions. 


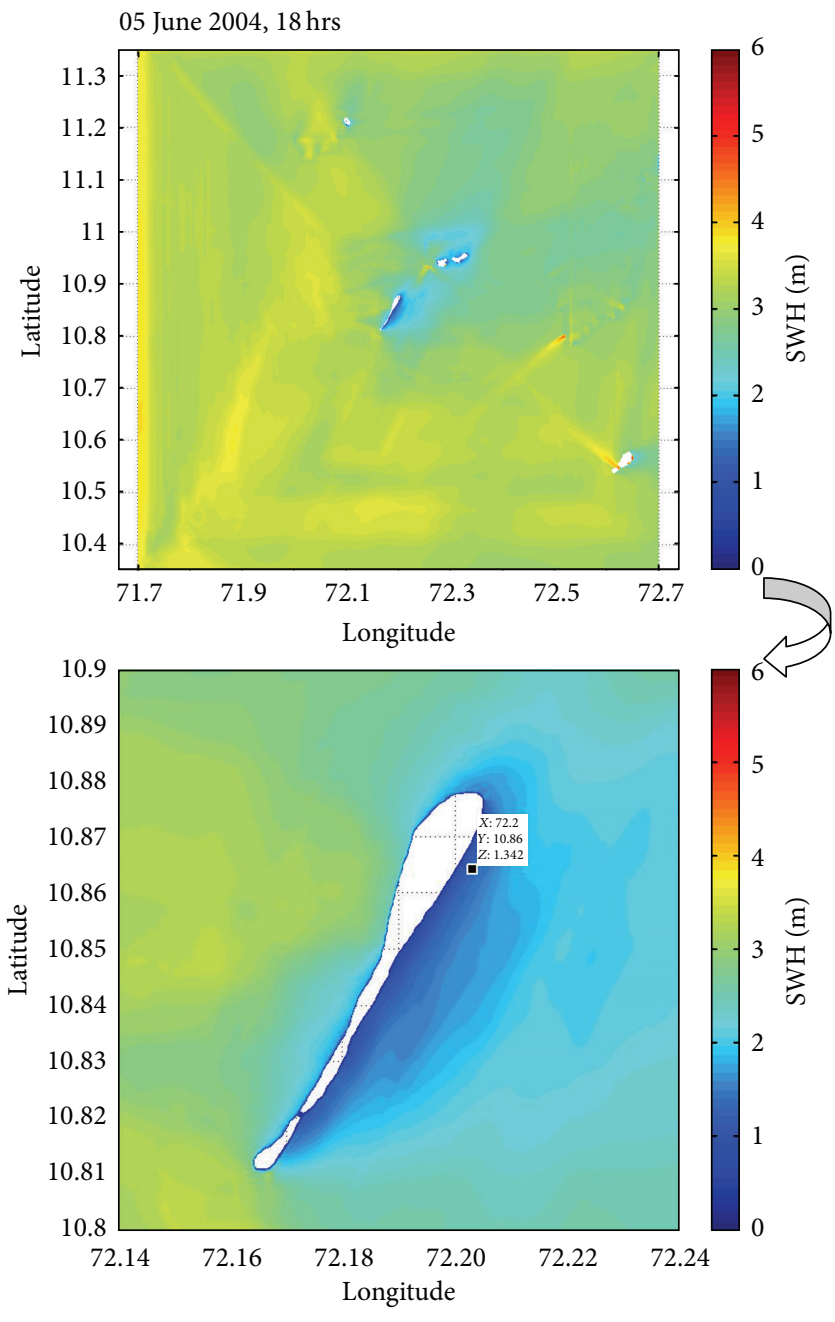

(a)
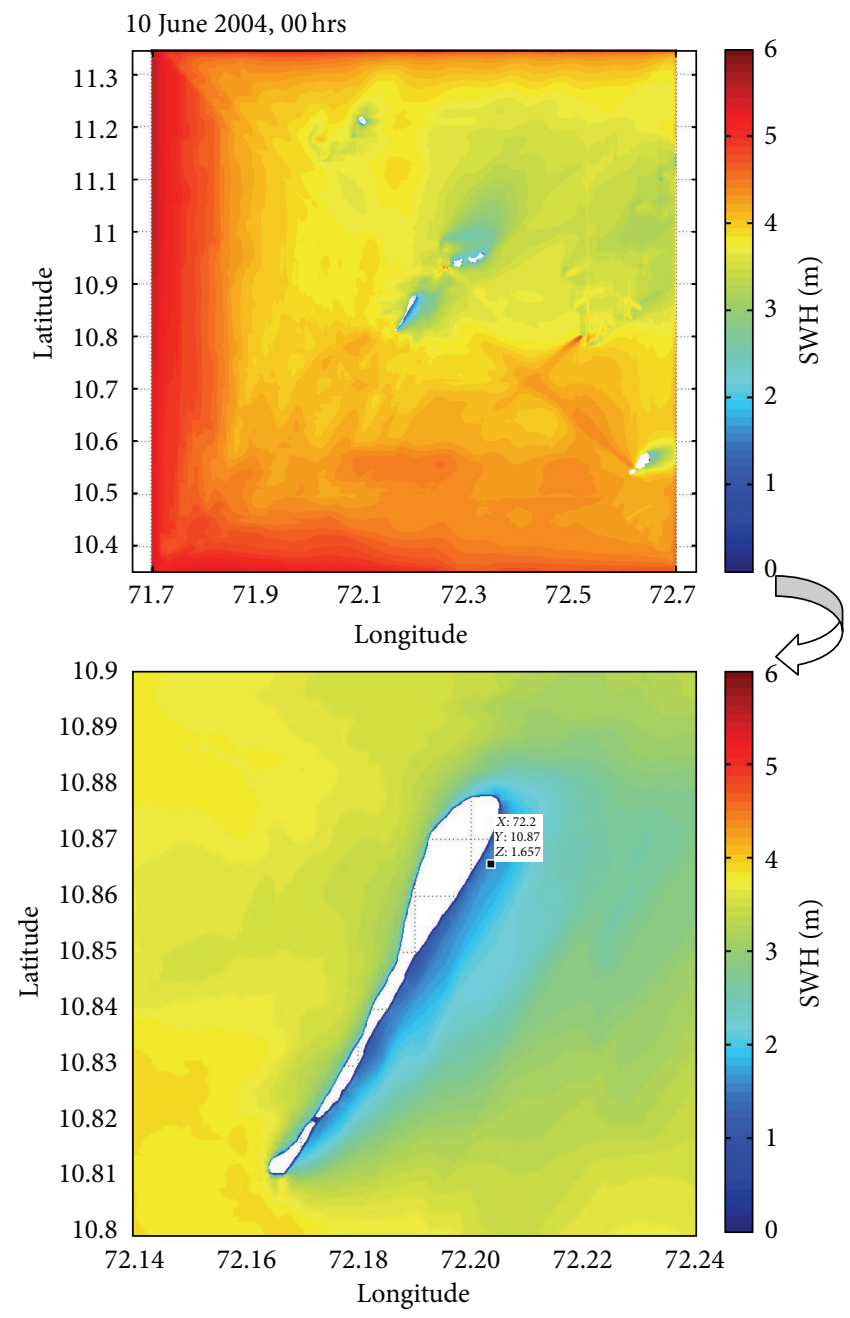

(b)

FIGURE 6: (a) SWH plots for SWAN run with unstructured grid at the beginning of the storm. (b) SWH plots for SWAN run with unstructured grid at the end of the storm.

08 June 2004,18 hrs

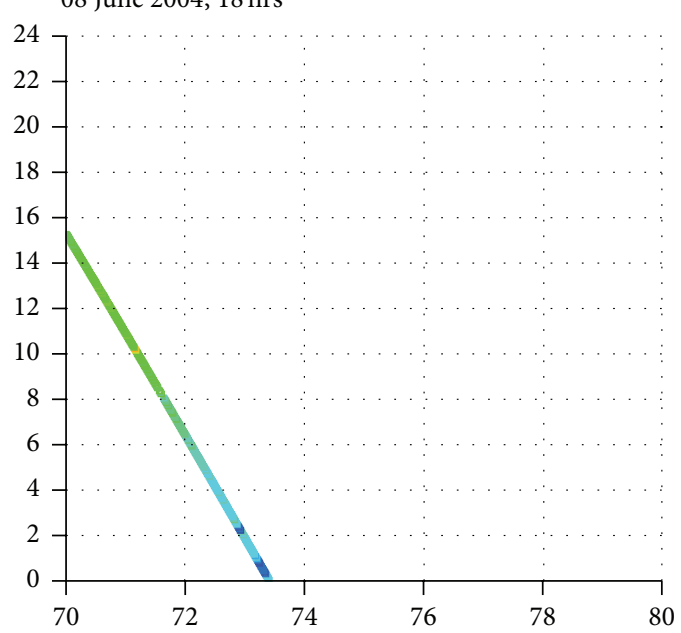

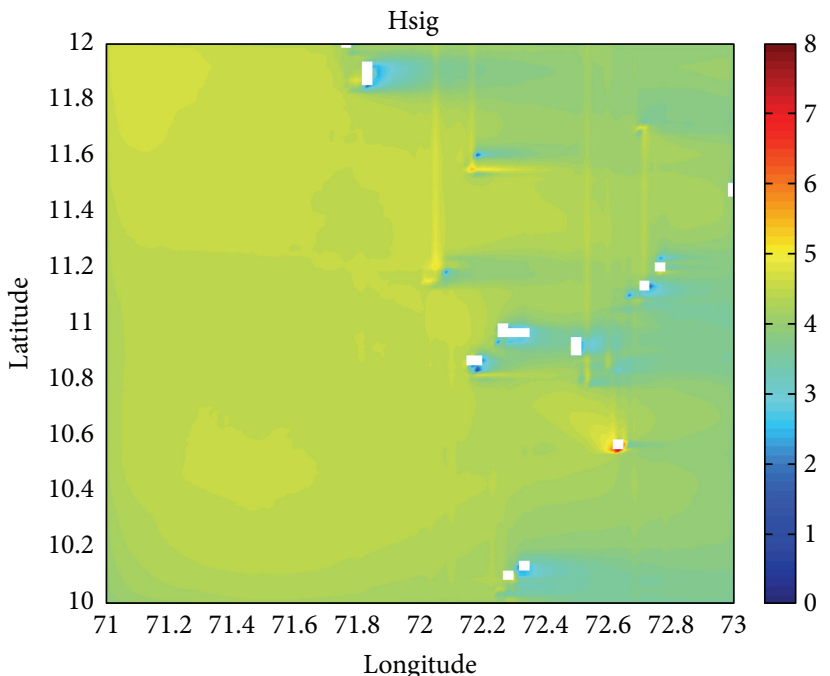

FIGURE 7: Envisat track for SWH and model computed SWH on 08 June 2004, 18 hours. 


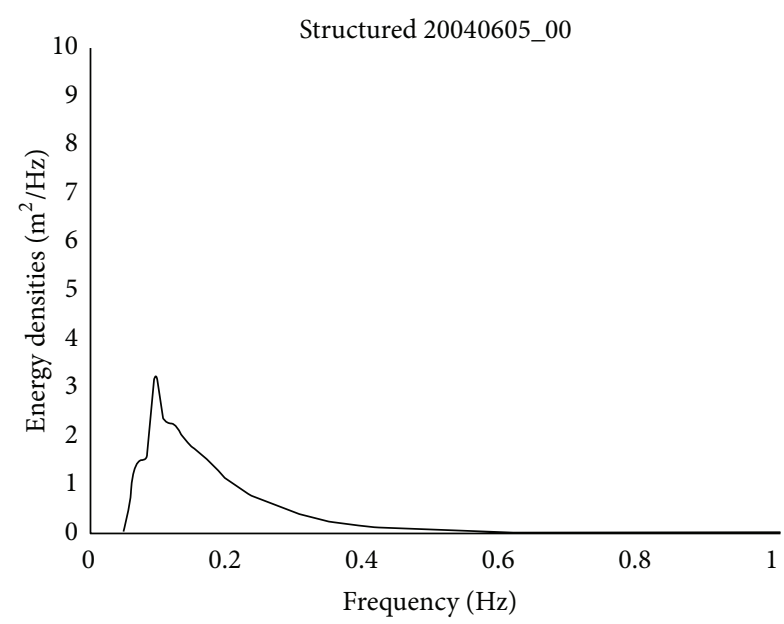

(a)

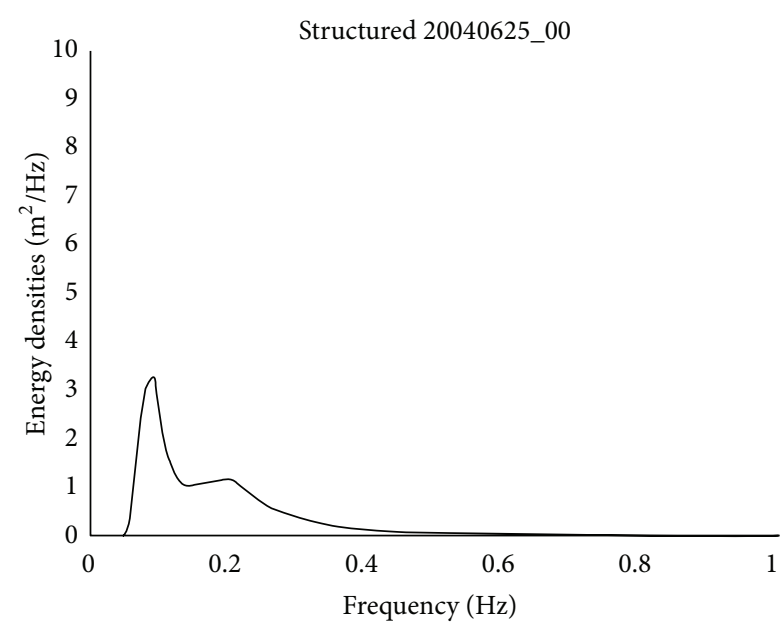

(c)

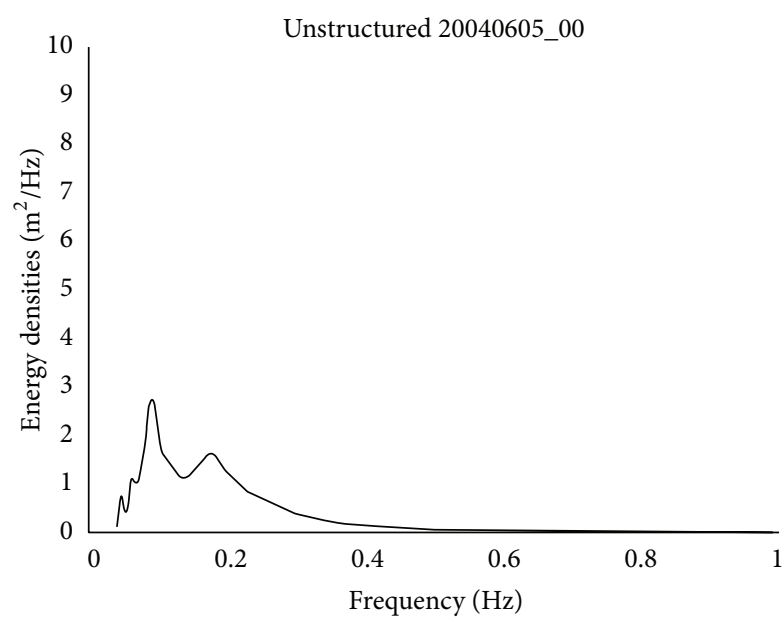

(b)

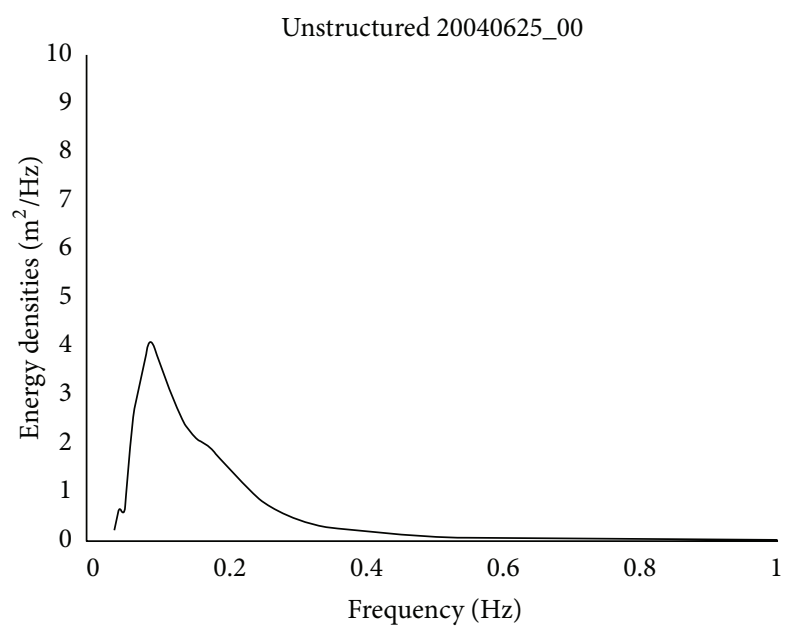

(d)

Figure 8: Energy density spectrum for 5 June and 25 June at $72.208^{\circ} \mathrm{E}, 10.879^{\circ} \mathrm{N}$.

\section{Acknowledgment}

The authors are thankful to Professor A. D. Rao, CAS, IIT Delhi, for his guidance and help in doing the experiments.

\section{References}

[1] V. Hoon and I. Babu, "Socioeconomic monitoring and assessment for coral reef management at Agatti Island, UT of Lakshadweep, CARESS/ LMRCC, India," 2012, http://docs.lib .gov/noaa_documents/CoRIS/SociEco_Monitoring_Lakshadweep .pdf.

[2] B. K. Carté, "Biomedical potential of marine natural products," BioScience, vol. 46, no. 4, pp. 271-286, 1996.

[3] P. Chandramohan, N. M. Anand, and B. U. Nayak, "Shoreline dynamics of the Lakshadweep islands," Indian Journal of Marine Sciences, vol. 22, no. 3, pp. 198-202, 1993.

[4] T. T. Ajith Kumar and T. Balasubramanian, "Bleaching of corals in Agatti-Lakshadweep, India: a window view," in Proceedings of the 12th International Coral Reef Symposium (ICRS '12), Cairns, Australia, July 2012.

[5] V. Hoon and C. Loper, "A decade of community-based socioeconomic monitoring in Lakshadweep, India 2001-2011," in
Proceedings of the 12th International Coral Reef Symposium (ICRS '12), Cairns, Australia, July 2012.

[6] B. G. Wagle and P. D. Kunte, "Photo-geomorphologic study of representative islands of Lakshadweep," Gondwana Geological Magazine, vol. 4, pp. 203-209, 1999.

[7] H. P. Gunther, K. Hasselmann, S. Hasselmann, and P. A. E. M. Janssen, “The WAM model cycle 4," DKRZ Report 4, DKRZ, Hamburg, Germany, 1992.

[8] G. J. Komen, L. Cavaleri, M. Donelan, K. Hasselmann, S. Hasselmann, and P. A. E. M. Janssen, Dynamics and Modelling of Ocean Waves, Cambridge University Press, Cambridge, UK, 1994.

[9] N. Booij, R. C. Ris, and L. H. Holthuijsen, "A third-generation wave model for coastal regions: 1. Model description and validation," Journal of Geophysical Research C: Oceans, vol. 104, no. 4, pp. 7649-7666, 1999.

[10] WAMDI Group, "The WAM model-a third generation ocean wave prediction model," Journal of Physical Oceanography, vol. 18, pp. 1775-1810, 1988.

[11] M. Zijlema, "Computation of wind-wave spectra in coastal waters with SWAN on unstructured grids," Coastal Engineering, vol. 57, no. 3, pp. 267-277, 2010. 

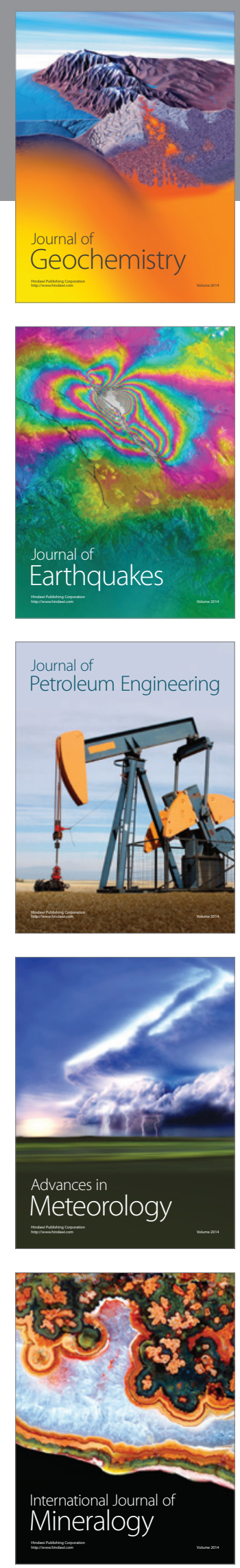
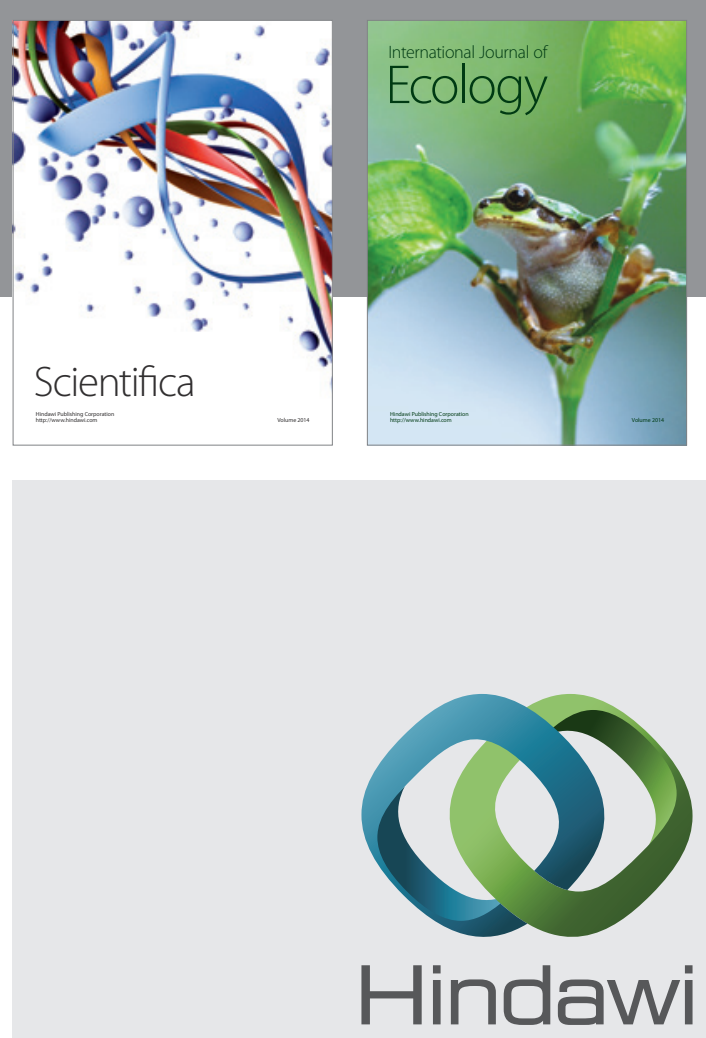

Submit your manuscripts at

http://www.hindawi.com
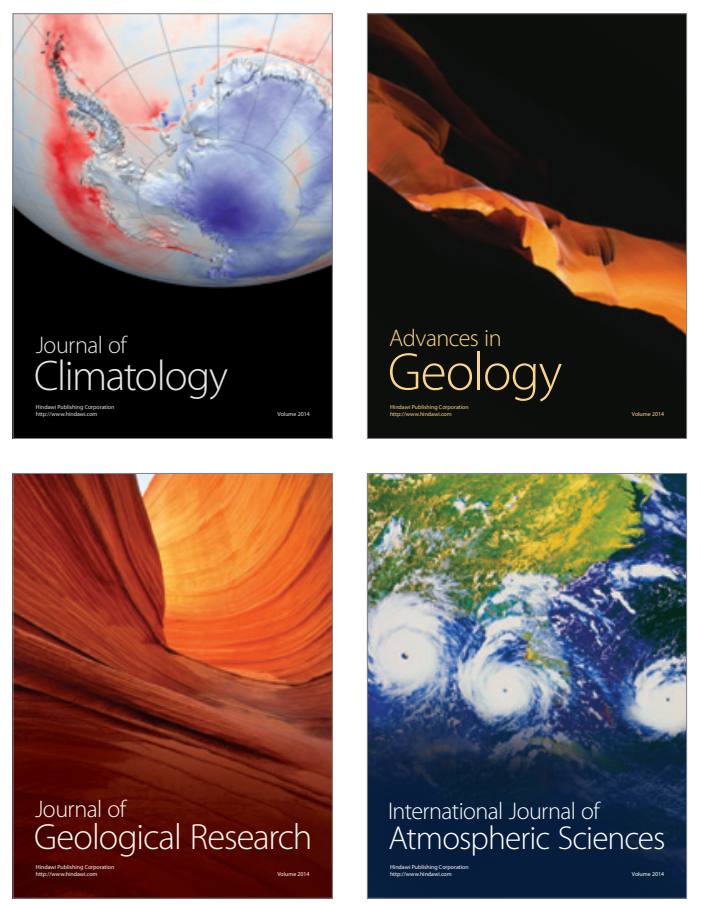

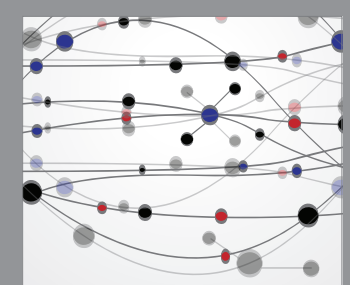

The Scientific

\section{World Journal}
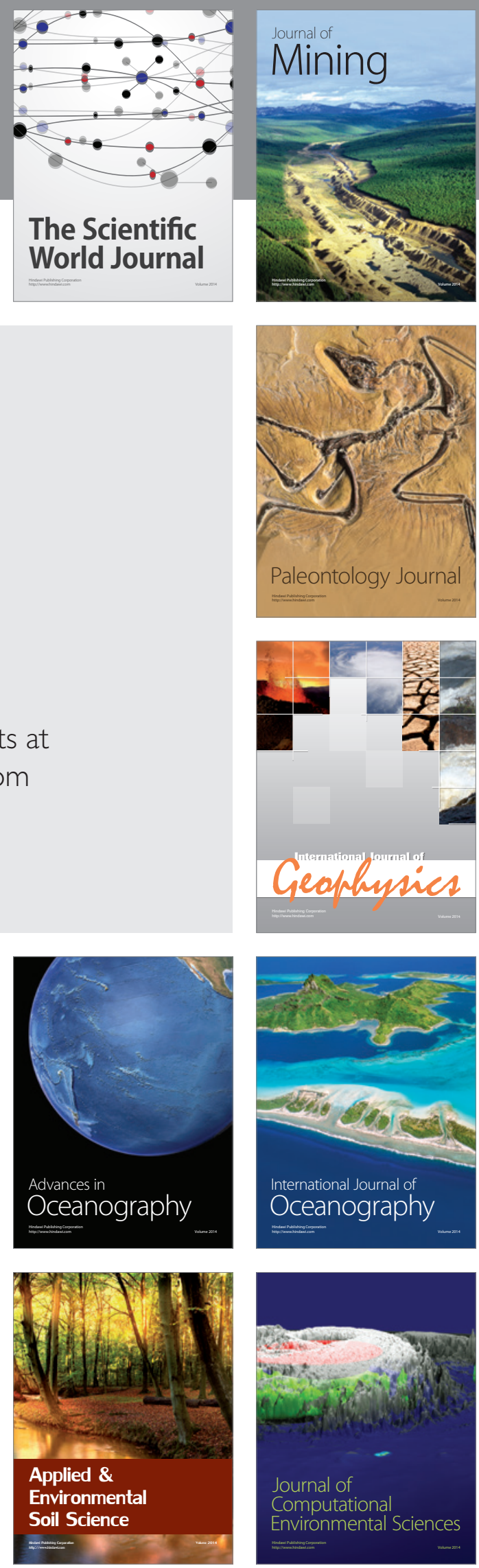